\title{
Static compliance of the respiratory system in COVID-19 related ARDS: an international multicenter study
}

Benoit Vandenbunder ${ }^{1 \dagger}$, Stephan Ehrmann ${ }^{2+}$, Michael Piagnerelli ${ }^{3}$, Bertrand Sauneuf ${ }^{4}$, Nicolas Serck ${ }^{5}$, Thibaud Soumagne ${ }^{6}$, Julien Textoris ${ }^{7,8}$, Christophe Vinsonneau ${ }^{9}$, Nadia Aissaoui ${ }^{10}$, Gauthier Blonz ${ }^{11}$, Giuseppe Carbutti ${ }^{12}$, Romain Courcelle ${ }^{13}$, Alain D'hondt ${ }^{14}$, Stephane Gaudry ${ }^{15}$, Julien Higny ${ }^{16}$, Geoffroy Horlait ${ }^{17}$, Sami Hraiech ${ }^{18,19}$, Laurent Lefebvre ${ }^{20}$, Francois Lejeune ${ }^{21}$, Andre Ly ${ }^{22}$, Jean-Baptiste Lascarrou ${ }^{23 \dagger}$, David Grimaldi ${ }^{24^{*}+}$ for the COVADIS study group

\begin{abstract}
Background: Controversies exist on the nature of COVID-19 related acute respiratory distress syndrome (ARDS) in particular on the static compliance of the respiratory system (Crs). We aimed to analyze the association of Crs with outcome in COVID-19-associated ARDS, to ascertain its determinants and to describe its evolution at day-14.

Methods: In this observational multicenter cohort of patients with moderate to severe Covid-19 ARDS, Crs was measured at day-1 and day-14. Association between Crs or Crs/ideal body weight (IBW) and breathing without assistance at day-28 was analyzed with multivariable logistic regression. Determinants were ascertained by multivariable linear regression. Day-14 Crs was compared to day-1 Crs with paired t-test in patients still under controlled mechanical ventilation.

Results: The mean $\mathrm{Crs}$ in 372 patients was $37.6 \pm 13 \mathrm{~mL} / \mathrm{cmH}_{2} \mathrm{O}$, similar to as in ARDS of other causes. Multivariate linear regression identified chronic hypertension, low $\mathrm{PaO}_{2} / \mathrm{FiO}_{2}$ ratio, low PEEP, and low tidal volume as associated with lower Crs/IBW. After adjustment on confounders, nor Crs [OR 1.0 (Cl 95\% 0.98-1.02)] neither Crs/IBW [OR 0.63 (CI 95\% 0.13-3.1)] were associated with the chance of breathing without assistance at day-28 whereas plateau pressure was [OR 0.93 (Cl 95\% 0.88-0.99)]. In a subset of 108 patients, day-14 Crs decreased compared to day-1 $\mathrm{Crs}$ ( $31.2 \pm 14.4 \mathrm{~mL} / \mathrm{cmH}_{2} \mathrm{O}$ vs $\left.37.8 \pm 11.4 \mathrm{~mL} / \mathrm{cmH}_{2} \mathrm{O}, p<0.001\right)$. The decrease in $\mathrm{Crs}$ was not associated with day- 28 outcome.

Conclusion: In a large multicenter cohort of moderate to severe COVID-19 ARDS, mean Crs was decreased below $40 \mathrm{~mL} / \mathrm{cmH}_{2} \mathrm{O}$ and was not associated with day-28 outcome. Crs decreased between day- 1 and day-14 but the decrease was not associated with day-28 outcome.
\end{abstract}

Keywords: SARS-COV-2, Plateau pressure, Respiratory mechanics, Mechanical ventilation, PEEP, Mortality, ICU

*Correspondence: david.grimaldi@erasme.ulb.ac.be

†Benoit Vandenbunder and Stephan Ehrmann are co-first authors

†Jean-Baptiste Lascarrou, David Grimaldi are co-last authors

${ }^{24}$ Soins Intensifs, Hôpital Erasme, ULB, Route de Lennik 808,

1070 Bruxelles, Belgium

Full list of author information is available at the end of the article

\section{Introduction}

Coronavirus disease 2019 (COVID-19) caused by the severe acute respiratory syndrome coronavirus 2 infection can have different clinical presentations but respiratory symptoms predominate, especially in patients admitted to intensive care units (ICU) [1]. The clinical original author(s) and the source, provide a link to the Creative Commons licence, and indicate if changes were made. The images or other third party material in this article are included in the article's Creative Commons licence, unless indicated otherwise in a credit line to the material. If material is not included in the article's Creative Commons licence and your intended use is not permitted by statutory regulation or exceeds the permitted use, you will need to obtain permission directly from the copyright holder. To view a copy of this licence, visit http://creativecommons.org/licenses/by/4.0/. The Creative Commons Public Domain Dedication waiver (http://creativeco mmons.org/publicdomain/zero/1.0/) applies to the data made available in this article, unless otherwise stated in a credit line to the data. 
presentation of the respiratory disease appeared at the beginning of the pandemic to be relatively homogenous: It involves mostly overweighed men aged 50 years or more, with cardiovascular comorbidities, and is characterized by severe hypoxemia and radiological ground glass opacities [2].

For the peculiar COVID-19 related acute respiratory distress syndrome (ARDS), some experts hypothesized that it could be separated in two main phenotypes according to lung mechanical properties: Patients at the early phase of the disease would have a high pulmonary compliance, whereas others patients may have low compliance, upfront or as transition from the first phenotype, because of self-induced lung injury [3]. Indeed, COVID19 hypoxemia seemed not to be fully explained by loss of aerated lung volume [4]. The classical "baby-lung" concept has been challenged as well as the use of the ARDS terminology to describe COVID-19 hypoxemic pneumonia [5]. In line with those pathophysiological reasoning, experts exerted physician to tailor respiratory therapy [such as tidal volume (Vt), positive end expiratory pressure (PEEP) or prone positioning] to each adequate phenotype at an individual level [6].

However, in autopsy studies, the predominant pulmonary histologic pattern of COVID-19 appeared to be diffuse alveolar damage, a characteristic feature of ARDS whatever the cause, associated with a high frequency of arterial thrombi [7-9]. Those results are compatible with autopsies being performed predominantly at late stages of the disease.

The two phenotypes concept has also been challenged by clinical data from monocentric studies with a limited number of patients showing that the mean compliance of the respiratory system (Crs) in COVID-19 ARDS patients was decreased around $30-40 \mathrm{~mL} / \mathrm{cmH}_{2} \mathrm{O}[10,11]$. There is then still intense debate about the actual Crs of COVID-19 patients' and subsequent therapeutic implications [12-14].

The multicenter prospective COVADIS study [15] included patients suffering from moderate to severe COVID-19 ARDS. We hypothesized that high Crs would be associated with the likelihood of breathing without assistance at day-28.

Our primary aim was to compare patients' characteristics and outcome according to low or high Crs. Secondary aims were to analyze the determinants of day- $1 \mathrm{Crs}$ in COVID-19 patients with moderate to severe ARDS and to describe the evolution of compliance at day-14 in a subset of patients.

\section{Patients and methods}

This study was compliant with STROBE guidelines.

\section{Study design}

This multicentric prospective observational study was performed in 21 ICUs in France $(n=12)$ and Belgium $(n=9)$. The COVID-19 pandemic began in France in the second week of March 2020 and one week later in Belgium.

\section{Patient population}

Inclusion criteria were:

- Age older than 18 years,

- moderate to severe ARDS according to Berlin definition [16] $\left(\mathrm{PaO}_{2} / \mathrm{FiO}_{2}\right.$ ratio $<200 \mathrm{mmHg}$ with a PEEP of at least $5 \mathrm{cmH}_{2} \mathrm{O}$ receiving invasive ventilation),

- positive SARS-CoV-2 RT-PCR.

Non-inclusion criteria were:

- Cardiac arrest before ICU admission,

- Extra corporeal membrane oxygenation (ECMO) requirement within the first $24 \mathrm{~h}$ of ICU admission,

- Chronic obstructive pulmonary disease with gold class 3 or 4 [17], or home oxygen therapy.

\section{Data collection}

The collected data have been described elsewhere [15]. Briefly, patients were included in participating ICUs between March 10, 2020 and April 15, 2020. We recorded demographics data and comorbidities using the Charlson comorbidity index [18]. We collected duration since symptoms onset and presence of coinfection. We recorded after optimization the following mechanical ventilation (MV) settings after intubation in supine position and initial ventilation optimization: total PEEP, plateau pressure (Pplat), Vt. We recorded administration of advanced therapies for acute respiratory failure during the ICU stay (neuromuscular blocking agents, inhaled pulmonary vasodilators, prone-positioning, and ECMO).

We calculated from measured variables the driving pressure as $\mathrm{DP}=$ Pplat-PEEP and the compliance of the respiratory system as $\mathrm{Crs}=\mathrm{Vt} / \mathrm{DP}$ in $\mathrm{mL} / \mathrm{cmH}_{2} \mathrm{O}$. To take into account the height of the patients, we calculated also the Crs/ideal body weight (IBW).

In patients still on volume/pressure-assisted controlled MV at day-14, we measured and calculated the same variables.

General guidelines for ARDS management were followed in all centers: targeting a $\mathrm{Vt}$ of $6 \mathrm{~mL} / \mathrm{kg}$ of ideal body weight (IBW), limited plateau pressure, prone positioning for severe hypoxemia [19]. NMBA were used with 
slight differences across centers [20]. The setting of PEEP was not protocolized and was left at the discretion of the attending physician.

\section{Primary objective and outcome}

The primary objective was to assess the outcome of COVID 19 patients requiring invasive mechanical ventilation according to initial Crs.

The prespecified primary endpoint was the number of ventilator free days (VFD) at day-28 [21] dichotomized in breathing without assistance $(\mathrm{VFD} \geq 1)$ or not $(\mathrm{VFD}=0)$.

\section{Secondary outcomes}

- Day-14 MV mode according to the following 4 predefined categories: (1) spontaneous breathing while extubated, (2) pressure support ventilation, (3) patient under volume/pressure-assisted controlled MV or ECMO, and (4) death

- Day-14 survival

- Day-28 survival

- Need for ECMO

- Pulmonary embolism

\section{Statistical analysis}

Discrete data were described by counts and percentage and compared using the Chi-square or Fisher's exact tests, as appropriate. Continuous data were described by the mean and standard deviation or by the median and interquartile range (IQR) and compared by the $t$ test or by the Mann-Whitney test as appropriate.

To identify the determinants of day- $1 \mathrm{Crs}$, we compared patients with the lowest Crs to patients with the highest. We further performed a multivariate linear regression including in the model variables describing patients' characteristics and ventilatory setting (Vt and PEEP), the Crs being the dependent continuous variable. We did the same analysis, the Crs/IBW being the dependent variable. We performed a backward selection eliminating variables with a $P$ value above 0.10 . Pplat and DP were not included in this analysis as mathematically linked to $\mathrm{Crs}$ and not set by the physician. Visual inspection of residues distribution was used to ensure the quality of the regressions.

We split Crs into quintiles to test its trend for association with day-28 outcome. Finally, we performed a multivariate backward logistic regression to analyze the association between breathing without assistance at day- 28 and Crs (as a continuous variable). We included in the models variables associated with the primary endpoint in univariate analysis with a $P$ value $<0.10$ and we forced $C r s$ as a continuous variable into the model, we did the same replacing Crs by $\mathrm{Crs} / \mathrm{IBW}$. Homesher-Lemeshow test and visual inspection were used to ensure the quality of the regressions. Backward selection was performed as described above. We included Pplat and Crs in the same model despite collinearity following published method $[22,23]$ assuming that if one of these two variables remained significantly correlated with the primary endpoint, this variable would be more informative than the other.

After reviewing of the manuscript, we performed post hoc analyses. We analyzed the association between Crs and our primary endpoint in the subgroups of patients with severe and moderate ARDS $(P / F \leq 100 \mathrm{mmHg}$ and $P / F$ between 101 and $200 \mathrm{mmHg}$ ). We also analyzed the correlation between $P / F$ ratio and $C r s$ across three categories of PEEP (5-8, 9-12 and above $\left.12 \mathrm{cmH}_{2} \mathrm{O}\right)$ using Pearson correlation.

To analyze the evolution of Crs at day-14, we measured day-14 Crs in patients under controlled MV as described above. We compared paired respiratory data (Vt, PEEP, DP, Crs) using the paired t-test or Wilcoxon ranking test according to distribution. We analyzed the association between day-1 Crs and day-14 Crs by univariate linear regression and by comparing delta $\mathrm{Crs}$ according to final outcome (breathing without assistance, still under invasive ventilation or death).

No imputation strategy was used for missing data. A $P$ value $<0.05$ was considered significant.

All analyses were performed using Stata (version 16, StataCorp, College Station, TX, USA).

\section{Ethics statement}

This study was approved by appropriate regulatory committee in France and Belgium in accordance with national regulation (2217488 and P2020/253). Each patient was informed about the study. In case of incompetency, next of kin were informed. The requirement for written informed consent was waived.

\section{Role of the funding source}

This study was not funded by any sources.

\section{Results}

Among the 416 patients included in the study, one withdrew consent and we could calculate the Crs in 372 (Additional file 1). The mean value of Crs was $37.6( \pm 13) \mathrm{mL} /$ $\mathrm{cmH}_{2} \mathrm{O}$, with a unimodal distribution (Fig. 1). 

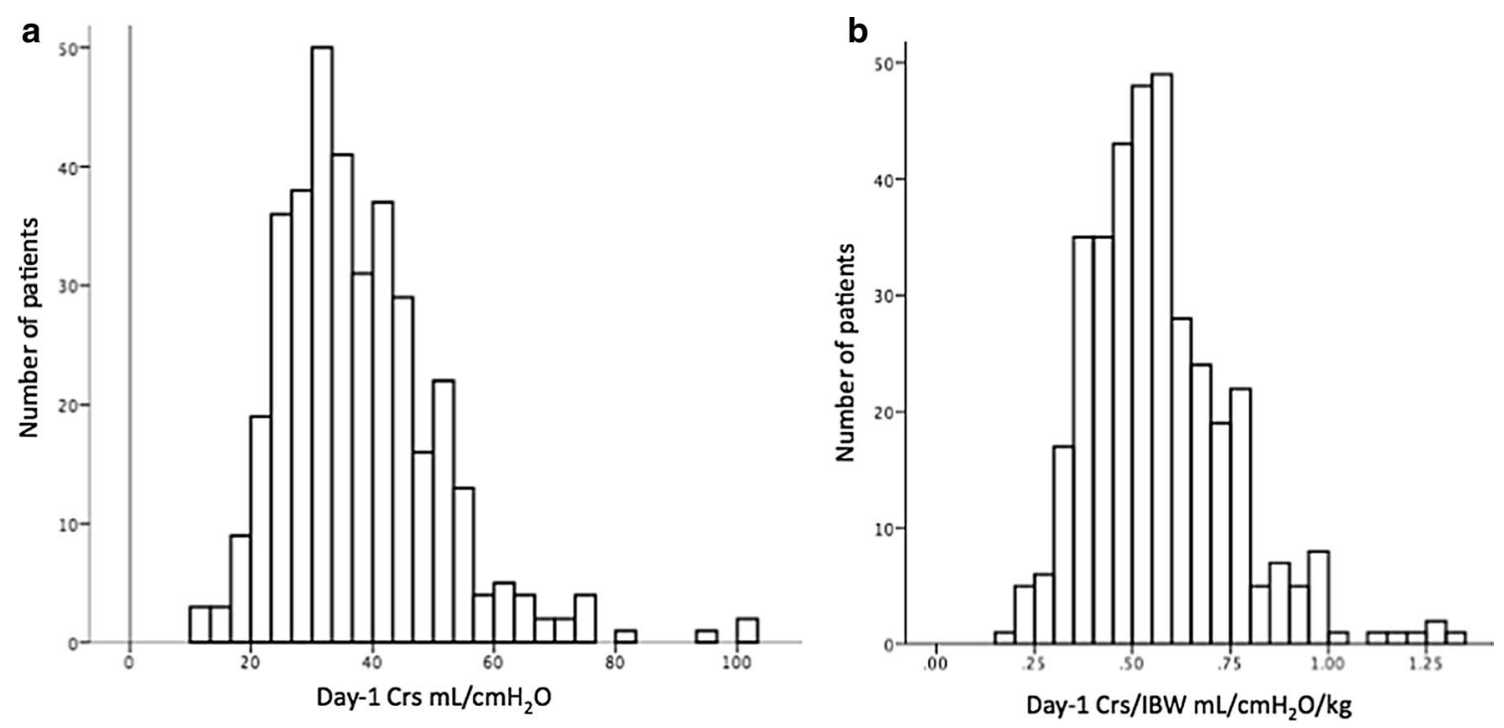

Fig. 1 Distribution of day-1 Crs (a) and day-1 Crs/IBW (b). Crs: compliance of the respiratory system, IBW: ideal body weight

\section{Baseline characteristics according to compliance (Table 1 and Additional file 1: Table 1)}

We compared patients' characteristics according to $\mathrm{Crs}$ dichotomized on the median value $\left(35.4 \mathrm{~mL} / \mathrm{cmH}_{2} \mathrm{O}\right)$. As shown in Table 1, compared to the patients with highest Crs, patients with the lowest Crs were more frequently women, suffered more frequently from chronic hypertension and had a slightly lower $\mathrm{PaO}_{2} / \mathrm{FiO}_{2}$ ratio, a lower PEEP with a higher Pplat and accordingly a higher DP. Patients were similarly treated with low Vt, large use of prone positioning and neuromuscular blocking agents.

We then analyzed the determinants of compliance (kept as a continuous variable) through multivariate linear regression and observed that female sex and chronic hypertension were associated with lower compliance whereas higher PEEP and Vt were associated with a higher compliance. Of note, neither BMI, pulmonary chronic disease nor duration of symptoms were associated with $\mathrm{Crs}$ (Additional file 2). To take into account the size of the patients, we analyzed also the determinants of the compliance/IBW ratio. In this analysis, sex was not associated with Crs/IBW whereas $P / F$ ratio was (Additional file 2 ).

Finally, as Crs is modified by PEEP, we looked at the correlation between Crs/IBW and $P / F$ according to three levels of PEEP. We observed that only the patients with a low PEEP $\left(5-8 \mathrm{cmH}_{2} \mathrm{O}\right)$ had a significant correlation between $\mathrm{Crs} / \mathrm{IBW}$ and $P / F$ ratio (Additional file 3).

\section{Outcome according to compliance (Table 2, Table 3, Fig. 2)}

The proportion of patients breathing without assistance, as well as the day-28 VFD, were similar between the two groups (Table 2); however, more patients with low Crs had died at day-28.

Among several secondary outcomes, we observed that patients with the lowest Crs required more often ECMO during ICU stay but overall, the mechanical ventilation mode at day 14 was not different. Pulmonary embolism was more frequently diagnosed in patients with the highest compliance.

Divided into quintiles, Crs was not associated with breathing without assistance at day-28 whereas Pplat was (Fig. 2). To adjust for confounders, we performed a multivariate logistic regression of variables associated with breathing without assistance at day 28 including age, sex, chronic hypertension, Charlson comorbidity index, $\mathrm{PaO}_{2} / \mathrm{FiO}_{2}$ ratio, Pplat, and Crs (Table 3). This analysis showed that $\mathrm{Crs}$ was not associated with likelihood of breathing without assistance at day-28, [OR 1.0 (CI 95\% $0.98-1.02)$ ] whereas plateau pressure was negatively associated with [OR 0.93 (CI 95\% 0.88-0.99)]. Sensitivity analysis considering $\mathrm{Crs}$ as a dichotomized variable provided the same results (data not shown). In a post hoc multivariate analysis including the same co-variables, Crs was not independently associated with Day-28 survival [OR 1.01 (CI 95\% 0.98-1.03)] whereas age, Pplat, $\mathrm{PaO}_{2} / \mathrm{FiO}_{2}$ ratio, and Charlson Comorbidity index were. Finally, in the subgroup of severe ARDS Crs was similar in patients breathing without assistance at day- 28 and 
Table 1 Patients' characteristics according to day-1 compliance of the respiratory system

\begin{tabular}{|c|c|c|c|}
\hline$n=372$ & $\begin{array}{l}\text { Crs }<35.4 \\
n=186\end{array}$ & $\begin{array}{l}\text { Crs }>35.4 \\
n=186\end{array}$ & $P$ value ${ }^{a}$ \\
\hline Age, mean $\pm S D$ & $63.5 \pm 10$ & $63.2 \pm 10.8$ & 0.78 \\
\hline Gender, men, $n(\%)$ & $130(70)$ & $154(83)$ & 0.005 \\
\hline Body mass index, $\mathrm{kg} / \mathrm{m}^{2}$, mean $\pm \mathrm{SD}$ & $29.9 \pm 5.1$ & $29.5 \pm 5$ & 0.47 \\
\hline Hypertension, $n(\%)$ & $116(62)$ & $94(51)$ & 0.02 \\
\hline Pulmonary chronic disease, $n(\%)$ & $24(13)$ & $26(14)$ & 0.88 \\
\hline Charlson comorbidity index, median (IQR) & $1(0-2)$ & $1(0-2)$ & 0.18 \\
\hline Charlson comorbidity index & & & 0.11 \\
\hline 0 & $69(37)$ & $86(46)$ & \\
\hline 1 & $53(29)$ & $38(20)$ & \\
\hline$\geq 2$ & $64(34$ & $62(33)$ & \\
\hline Time from symptoms onset, days, median (IQR) & $7(5-10)$ & $8(5-10)$ & 0.02 \\
\hline Coinfection, $n(\%)$ & $19(10)$ & $23(12)$ & 0.62 \\
\hline $\mathrm{PaO}_{2} / \mathrm{FiO}_{2}(\mathrm{mmHg})$, mean $\pm \mathrm{SD}$ & $123 \pm 48$ & $132 \pm 53$ & 0.07 \\
\hline $\begin{array}{l}\text { Tidal volume }(\mathrm{ml} / \mathrm{kg} \text { IBW }) \text {, mean } \pm \text { SD } \\
n=180 / 185\end{array}$ & $6.2 \pm 0.9$ & $6.3 \pm 0.8$ & 0.12 \\
\hline $\operatorname{PEEP}\left(\mathrm{cmH}_{2} \mathrm{O}\right)$, mean $\pm \mathrm{SD}$ & $11.1 \pm 2.9$ & $12 \pm 2.6$ & 0.002 \\
\hline Plateau pressure $\left(\mathrm{cmH}_{2} \mathrm{O}\right)$, median $(\mathrm{IQR})$ & $26(23-28)$ & $22(20-24)$ & $<0.001$ \\
\hline Driving Pressure $\left(\mathrm{cmH}_{2} \mathrm{O}\right)$, median (IQR) & $14(12-16)$ & $9.5(8-11)$ & $<0.001$ \\
\hline Inhaled nitric oxide, $n(\%)$ & $21(11)$ & $23(12)$ & 0.87 \\
\hline Prone positioning, $n(\%)$ & $152(82)$ & $147(79)$ & 0.51 \\
\hline Neuromuscular blocking agents, $n$ (\%) & $162(87)$ & $151(81)$ & 0.16 \\
\hline Antiviral treatment, $n(\%)$ & $143(77)$ & $158(85)$ & 0.06 \\
\hline $\begin{array}{l}\text { Corticosteroids }{ }^{b}, n(\%) \\
n=175 / 182\end{array}$ & $34(19)$ & $43(24)$ & 0.37 \\
\hline Macrolides & $112(60)$ & $116(62)$ & 0.75 \\
\hline
\end{tabular}

$S D$ standard deviation, IQR interquartile range, IBW ideal body weight; $C r s$ static compliance of the respiratory system

a $P$ value was calculated by Fisher exact test, $t$ test or Mann-Whitney test as appropriate

b Some patients were included in a RCT steroids versus placebo, steroids were mostly given late in the ICU stay

in patients who did not $(38.7 \pm 11.3$ vs $35.1 \pm 11.8 \mathrm{~mL} /$ $\mathrm{cmH}_{2} \mathrm{O}, P=0.11$ ), the difference was even less pronounced in moderate ARDS patients (data not shown).

\section{Day 1-day 14 evolution of compliance (Table 4, Fig. 3)}

At day-14, Crs could be calculated in 108 patients still in controlled ventilation mode. The individual day-14 Crs was lower and strongly correlated with the day- $1 \mathrm{Crs}\left(R^{2}=0.87 p<0.001\right.$, Fig. 3a). Indeed, the mean Crs decreased from $37.8 \pm 11.4 \mathrm{~mL} / \mathrm{cmH}_{2} \mathrm{O}$ to $31.2 \pm 14.4 \mathrm{~mL} / \mathrm{cmH}_{2} \mathrm{O}(p<0.001$, paired $t$ test $)$. This decrease was explained by the increase in driving pressure as Vt decreased between day- 1 and day-14. Conversely, Pplat was similar between day-1 and day-14 (Table 4).

The decrease of Crs between day- 1 and day- 14 was similar in patients that were extubated before day- 28 and in those that were still under mechanical ventilation at this time point. Patients who died before day- 28 had a slightly more pronounced decrease of Crs (Fig. 3b). This translated into a higher, although not significant, difference in Crs between day 14 and day 1: $-5.6 \pm 12.2$; $5.8 \pm 13.8 ;-8.8 \pm 12.1 \mathrm{~mL} / \mathrm{cmH}_{2} \mathrm{O}(\mathrm{p}=0.55)$ in patients extubated, still on mechanical ventilation or deceased at day- 28 , respectively.

\section{Discussion}

In this multicenter observational study of moderate to severe ARDS complicating COVID-19, our observations were: mean static compliance of the respiratory system was $37.6 \mathrm{~mL} / \mathrm{cmH}_{2} \mathrm{O}$ with a monomodal distribution, while PEEP was set between 10 and $15 \mathrm{cmH}_{2} \mathrm{O}$ for $78 \%$ of patients and Vt was tightly set between 6 and $7 \mathrm{~mL} /$ $\mathrm{kg}$ IBW. After adjustment, day-1 Crs was not associated with neither the chance of breathing without assistance at day-28 nor day-28 survival, whereas Pplat was. At day14 , in patients still in controlled ventilation mode, compliance had decreased in average but this decrease was not associated with day- 28 status. 


\begin{tabular}{|c|c|c|c|}
\hline & $\begin{array}{l}\text { Crs }<35.4 \\
n=186\end{array}$ & $\begin{array}{l}\text { Crs }>35.4 \\
n=186\end{array}$ & $P$ value ${ }^{a}$ \\
\hline $\begin{array}{l}\text { Breathing without assistance } \\
\text { at day- } 28, n(\%)\end{array}$ & $66(36)$ & $81(44)$ & 0.17 \\
\hline Day-28 VFD, median (IQR) & $0(0-11)$ & $0(0-12.5)$ & 0.20 \\
\hline \multicolumn{4}{|l|}{ Day-14 Ventilatory mode } \\
\hline Death & $50(27)$ & $38(20)$ & 0.48 \\
\hline Controlled or W-ECMO & $60(33)$ & $65(35)$ & \\
\hline Pressure support & $38(21)$ & $42(23)$ & \\
\hline Extubated & $35(19)$ & $41(22)$ & \\
\hline Alive at day-14, n (\%) & $135(73)$ & $148(80)$ & 0.14 \\
\hline Alive at day-28, n (\%) & $110(60)$ & $131(71)$ & 0.03 \\
\hline Pulmonary embolism, $n$ (\%) & $18(10)$ & $33(18)$ & 0.03 \\
\hline V-ECMO, n (\%) & $31(17)$ & $15(8)$ & 0.02 \\
\hline
\end{tabular}

IQR interquartile range, $V V-E C M O$ veno-venous extracorporeal membrane oxygenation, VFD ventilator free days, Crs static compliance of the respiratory system

a $P$ value was calculated by Fisher exact test, $t$ test or Mann-Whitney test as appropriate

Table 3 Factors associated with breathing
without assistance at day-28

\begin{tabular}{lll}
\hline & Adjusted OR $^{\mathbf{a}}$ & $\mathrm{Cl} \mathrm{95 \%}^{\mathbf{a}}$ \\
\hline Age, per year & 0.95 & $0.93-0.97$ \\
Gender, men & 0.5 & $0.3-0.8$ \\
$\mathrm{PaO}_{2} / \mathrm{FiO}_{2}$ per $\mathrm{mmHg}$ & 1.006 & $1.002-1.01$ \\
Plateau pressure per $\mathrm{CmH}_{2} \mathrm{O}$ & 0.93 & $0.88-0.99$ \\
Model using absolute values of $\mathrm{Crs}$ & & \\
Crs per $\mathrm{mL} / \mathrm{cmH}_{2} \mathrm{O}$ & 1.0 & $0.98-1.02$ \\
Model using indexed values of $\mathrm{Crs} / \mathrm{IBW}$ & & \\
$\mathrm{Crs} / \mathrm{IBW}$ per $\mathrm{mL} / \mathrm{cmH}_{2} \mathrm{O} / \mathrm{kg}$ IBW & 0.63 & $0.13-3.1$ \\
\hline
\end{tabular}

OR odds ratio, $\mathrm{Cl}$ confidence interval, $\mathrm{Cr}$ s static compliance of the respiratory system

a Adjusted odds ratios (ORs), and their confidence interval (CI) were determined using multivariate logistic regression with backward selection. Variables entered in the models were age, sex, chronic hypertension, Charlson comorbidity index, plateau pressure, compliance of the respiratory system, and $\mathrm{PaO}_{2} / \mathrm{FiO}_{2}$ ratio in model 1 replacing $\mathrm{Crs}$ by $\mathrm{Crs} / \mathrm{BW}$ in model 2. As $\mathrm{Crs} / \mathrm{IBW}$ was not retained in the final model, $O R$ are identical for the other variables

$n=365$ and 359 patients for model 1 and 2 , respectively

Patients' characteristics in our cohort were similar to previous findings in other countries [24, 25]. Patients were mostly overweighed males between 50 and 70 years of age, with mostly mild cardiovascular comorbidities. In line with ARDS guidelines [19], physicians set Vt near $6 \mathrm{~mL} / \mathrm{kg}$ of IBW, PEEP at moderate to high level, used largely prone positioning and paralysis. Thus, in this large, multicentric, international cohort of COVID-19 ARDS patients, one may consider typical, the mean compliance at day-1 after intubation was $37.6 \mathrm{~mL} /$ $\mathrm{cmH}_{2} \mathrm{O}$. Of note this measure was done after ventilation optimization (Vt and PEEP setting) but not on a prespecified level of PEEP. It seems that for a given patient with COVID-19 ARDS, Crs is not that much influenced by PEEP even if in some individuals, a great variability has been observed when comparing 2 PEEP levels [26-28]. Early small monocentric studies reported mean $\mathrm{Crs}$ as high as $50 \mathrm{~mL} / \mathrm{cmH}_{2} \mathrm{O}[4,26,29]$, but larger albeit still monocentric studies reported lower values ranging from 28 to $44 \mathrm{~mL} / \mathrm{cmH}_{2} \mathrm{O}[10,11,30,31]$. In a large multicenter study including COVID-19 ARDS published at the date of writing, median compliance was $35 \mathrm{~mL} / \mathrm{cmH}_{2} \mathrm{O}$ but could be measured in only $40 \%(n=296)$ of the patients [32]. We found exactly the same median compliance $\left(35.4 \mathrm{~mL} / \mathrm{cmH}_{2} \mathrm{O}\right)$ in a larger number of patients with a high completion rate of data (nearly 90\%). In a report of 300 ARDS patients from seven ICUs in Italy, median compliance was $41 \mathrm{~mL} / \mathrm{cmH}_{2} \mathrm{O}$, slightly higher than the one we observed [33]. As highlight by others, this mean compliance is similar $[12,32]$ or slightly higher $[28,33]$ to that observed in non-COVID-19 ARDS [34] contradicting the idea of a specifically high compliance in COVID-19 ARDS. We may hypothesize that at the beginning of the pandemic, early intubation was of common practice and led to an overestimation of the mean compliance of COVID-19 ARDS due to intubation of patients with low severity $[35,36]$. Another hypothesis would be that the high initial rate of pulmonary embolism in COVID-19 [37, 38] before increase of thrombophrophylaxis [39] lowered the $\mathrm{PaO}_{2} / \mathrm{FiO}_{2}$ ratio and explained in some patients the discrepancy between severity of hypoxemia and alteration of respiratory mechanics.

We identified determinants of day-1 Crs. Interestingly, chronic hypertension was associated with a lower Crs but our study was not designed to provide explanation for these findings. Female sex was associated with a lower compliance due to the association between compliance and height. Indeed, the sex was not associated with the static compliance/IBW ratio. Vt and PEEP were associated with higher compliance (not meaning a causal relationship), but we may hypothesize that high PEEP was associated with significant alveolar recruitment although this phenomenon is not constant in COVID19 ARDS [26, 30]. We observed a univariate association between compliance and $P / F$ ratio, which was more pronounced in low level of PEEP, suggesting that some of these patients could have been recruitable. PEEP-induced recruitment may be evaluated by the recruitment-toinflation ratio to more precisely analyze the relationship between PEEP setting and Crs; however, such detailed lung mechanics assessment was beyond the scope of this multicenter large-scale study [40]. 


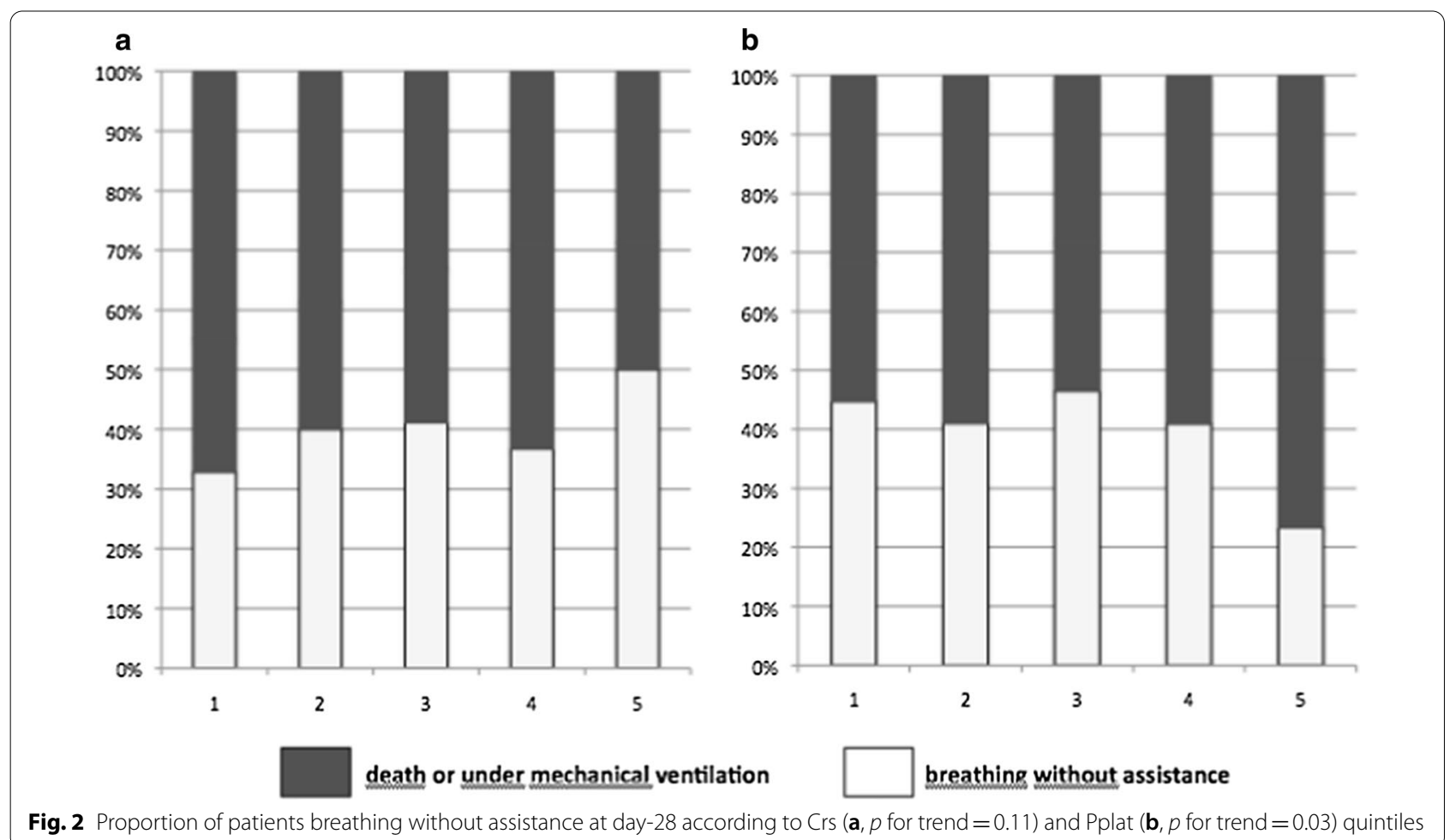

Table 4 Change in respiratory system mechanics from day-1 to day-14

\begin{tabular}{lllc}
\hline $\mathbf{n = 1 0 8}$ & Day $\mathbf{1}$ & Day $\mathbf{1 4}$ & $\boldsymbol{P}_{\text {value }}$ \\
\hline Positive end expiratory pressure $\left(\mathrm{cmH}_{2} \mathrm{O}\right)$, mean $\pm \mathrm{SD}$ & $11.8 \pm 2.7$ & $10.3 \pm 2.8$ & $<0.001$ \\
Plateau pressure $\left(\mathrm{cmH}_{2} \mathrm{O}\right)$, median $(\mathrm{IQR})$ & $23.5(21-27)$ & $23.5(20-26.5)$ & 0.49 \\
Driving pressure $\left(\mathrm{CmH}_{2} \mathrm{O}\right)$, median $(\mathrm{IQR})$ & $11(9-14)$ & $13(10-16)$ & $<0.001$ \\
Tidal volume $(\mathrm{ml} / \mathrm{kg} \mathrm{IBW})$, mean $\pm \mathrm{SD}$ & $6.2 \pm 0.8$ & $5.6 \pm 1.5$ & $<0.001$ \\
$\mathrm{Crs}\left(\mathrm{mL} / \mathrm{cmH}_{2} \mathrm{O}\right)$, mean & $37.8 \pm 11.4$ & $31.2 \pm 14.4$ & $<0.001$ \\
\hline
\end{tabular}

$S D$ standard deviation, IQR interquartile range, IBW ideal body weight, $C r$ static compliance of the respiratory system

a $P$ value was calculated by paired t-test or Wilcoxon test as appropriate

Regarding Vt, the association with higher Crs is counterintuitive and probably reflects that the investigators decreased Vt to limit Pplat as a consequence of low Crs. Interestingly, we were able to confirm in a large cohort and after adjustment the lack of association between symptom duration and Crs [30].

Crs was not associated with the likelihood of breathing without assistance or with survival at day-28. This is in line with findings in classical ARDS as highlighted in the Berlin consensus paper where compliance did not add to the mortality prediction in severe ARDS [16]. Conversely, in our study, Pplat was strongly associated with day-28 outcomes (breathing without assistance and survival) even in multivariate analyses. It is known that high Pplat (above $28-30 \mathrm{cmH}_{2} \mathrm{O}$ ) is associated with ARDS mortality and thus guidelines recommend to target a Pplat below this threshold $[19,41]$, our study could, however, plead for a COVID-19-specific lower Pplat threshold as the association between Pplat and outcome was observed despite $90 \%$ of the present cohort having a Pplat $\leq 28$ $\mathrm{cmH}_{2} \mathrm{O}$. We observed a limited dispersion of the respiratory variables, which ensure a certain degree of homogeneity. However, it may preclude the generalizability of our findings in patients, which could have a strikingly different driving pressure as a result of higher $\mathrm{Vt}$ and/or lower PEEP. This has been already advocated as a possible explanation of discrepancy regarding the importance of DP as a prognostic factors in ARDS [23].

The last result is our original data on Crs evolution up to day 14. We observed in a subset of patients that $\mathrm{Crs}$ 

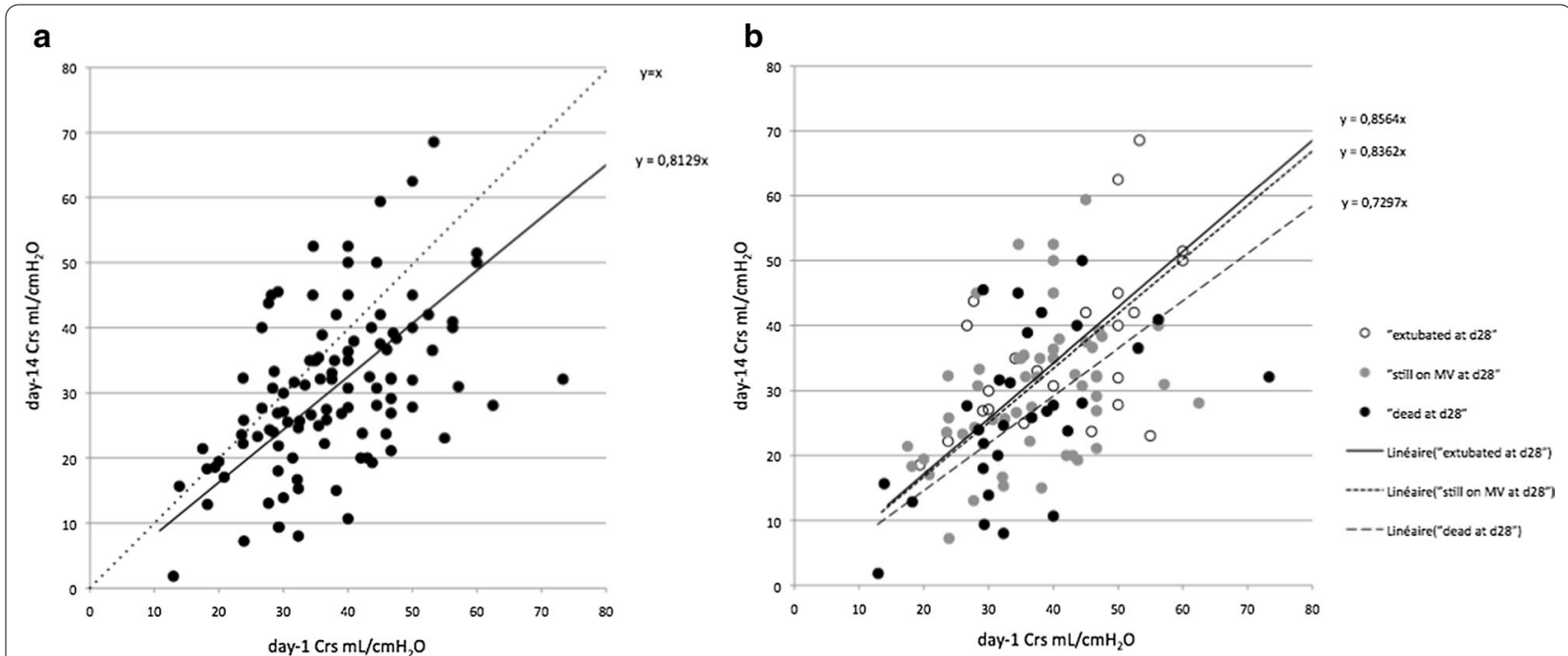

Fig. 3 Relation between day-1 and day-14 Crs $(n=108)$. a shows the regression line (continuous) between day-14 and day-1 Crs compared to the $y=x$ (dotted line). $\mathbf{b}$ shows the same data according to three day-28 outcomes: patients extubated (empty circles) patients still on mechanical ventilation (grey circles) and patients who died (black circles) and their respective regression lines

decreased between these two time points evoking either a fibrotic evolution of "late ARDS" or a loss of lung tissue aeration due to worsening lung disease [42, 43]. Few studies have provided repeated measurement of Crs: It seems not decrease at day 5 and $7[10,11]$. In the multicenter study of Ferrando et al., a small subset of patients had $\mathrm{Crs}$ measurement until day $14(n=61)$ and $\mathrm{Crs}$ seemed to decrease after day 10 [32]. However, in these three studies, paired data were not shown, making difficult the interpretation of the results. Conversely, we analyzed paired values of compliance and observed a clear decrease. This observation is remarkable as, in the same time, physicians markedly decreased the Vt and the PEEP in order to keep Pplat in the same range that at day-1. This suggests that the decrease in Crs had been minimized by the prevention of end inspiratory overdistension. Maybe due to this adaptation and/or a lack of power, the decrease in Crs was not associated with outcome. Despite the lack of association with day-28 survival, the decrease in Crs could be associated with long-term respiratory sequelae and this should be analyzed in further studies. The main limit interpreting this set of results is that they concern less than $1 / 3$ of the patients, the others being either dead, extubated, or on weaning process at day 14. This unavoidable bias limits the interpretation to a specific subset of patients, in whom, even at day-14, the data completion rate was as high as $85 \%(108 / 125)$ of day-14 Crs measurements.

Finally, we highlight the limitations of our observational study: The respiratory settings and patients' management were not standardized although collected variables suggest high similarity in treatment strategies and adherence to ARDS guidelines. Non-measured confusion biases may exist anyway. We did not collect any ICU specific severity score but these scores have been developed to compare patients with different diseases in the ICU; furthermore, the Charlson Comorbidity index associated with gender and age has been shown to predict mortality with good accuracy and thus reflecting severity of disease [44]. Missing data, albeit scarce, may impact our results. With the choice of a pragmatic design, favoring feasibility during the COVID-19 crisis, we strongly limited the number of collected variables so that we were not able to report important but more complicated data such as transpulmonary pressure, recruitability, shunt fraction, or hemodynamic parameters as well as daily ventilator settings.

\section{Conclusion}

In moderate to severe ARDS COVID-19 patients, we observed a unimodal distribution of the compliance of the respiratory system around a mean value of $37 \mathrm{~mL} /$ $\mathrm{cmH}_{2} \mathrm{O}$ as usually observed in non-COVID-19 ARDS. Higher compliance values were not associated with faster weaning of mechanical ventilation nor with improved survival in multivariate analyses. Mean compliance decreased from day-1 to day-14. Further studies are needed to analyze the consequence of such evolution. 


\section{Supplementary Information}

The online version contains supplementary material available at https://doi. org/10.1186/s13054-020-03433-0.

\author{
Additional file 1: Flow chart of the study. \\ Additional file 2: Determinants of day-1 Compliance and Compliance/ \\ IBW.
}

Additional file 3: Crs, Crs/IBW and P/F ratio according to Peep level.

\section{Acknowledgements}

We thank Mariana Ismael for Castor EDC (Amsterdam, The Netherlands) for technical support to design eCRF. We thank COVADIS study group investigators: Patrick Biston, Intensive Care. CHU-Charleroi, Marie Curie. Université Libre de Bruxelles. 140, Chaussée de Bruxelles. 6042-Charleroi, Belgium. Gwenhael Colin, Medecine Intensive Reanimation, CHD Vendée, site de la Roche sur Yon, Les Oudairies, 85000 La Roche Sur Yon, France. Oriane de Maere, Department of Intensive Care,CHR Mons-Hainaut, Mons, Belgium. Nathan Ebstein, Réanimation médico-chirurgicale CHU Avicennes, Université Sorbonne Paris Nord, Bobigny, France. Frederic Foret, Unité de soins intensifs, CHU Dinant Godinne, site Dinant, Belgium. Thibault Helbert, Réanimation polyvalente Centre Hospitalier du pays d'Aix, Aix en Provence, France. Jean-Baptiste Mesland, Department of Intensive Care, centres hospitaliers de Jolimont, La Louvière, Belgium. Celine Monard, Service de réanimation, Hospices Civils de Lyon, 5 Place D'Arsonval, Lyon, France. Nicolas Mongardon, Service d'anesthésie-réanimation chirurgicale Unité de réanimation chirurgicale polyvalente Hôpitaux Universitaires Henri Mondor, Créteil, France. Gregoire Ottavy, Medecine Intensive Reanimation, CHU Nantes, 30 Boulevard Jean Monnet, 44093 Nantes Cedex 9, France. Thomas Pasau, CHU UCL Namur, site Godinne, Av. Dr G. Therasse 15530 , Yvoir, Belgium. Gael Piton, Médecine Intensive Réanimation, CHU Besançon, 3 Boulevard FLEMING, 25030 Besançon, France. Zoe Pletschette, Soins Intensifs, Hôpital Erasme, ULB, Route de Lennik 808, 1070 Bruxelles, Belgium. Ester Ponzetto, Unité de soins intensifs, Clinique Saint Pierre, Ottignies, Belgium. Caroline Sejourne, Service de Médecine Intensive Réanimation, $\mathrm{CH}$ Germon et Gauthier, Béthune, France. Piotr Szychowiak, Médecine Intensive Réanimatio, CHRU de Tours, Tours, France. Xavier Souloy, Réanimation - Médecine Intensive, Centre Hospitalier Public du Cotentin, BP208, 50102 Cherbourg-en-Cotentin, France. Aude Sylvestre, Médecine Intensive Réanimation, Assistance Publique - Hôpitaux de Marseille, Hôpital Nord, , 13015, Marseille, France. Nicolas Tartrat, Groupe des anesthésistes réanimateurs, Hôpital Privé d'Antony, Antony, France. Cedric Vanbrussel, Unité de soins intensifs, Clinique Notre Dame de Grâce, Gosselies, Belgium.

\section{Take home message}

Compliance in COVID-19 related ARDS was low in average and unimodally distributed. Compliance was not associated with breathing without assistance at day-28 whereas plateau pressure was. Compliance decreased at day-14 evoking a potential fibrotic process.

\section{Authors' contributions}

$\mathrm{DG}, \mathrm{BV}, \mathrm{SE}$, and JBL were responsible for the study concept and design; all authors contributed to ; DG, BV, JBL, SE contributed to analysis and interpretation of the data; DG and SE contributed to drafting of the manuscript; all authors contributed to acquisition of the data and critical revision of the manuscript for important intellectual content. All authors read and approved the final manuscript. The corresponding author had full access to all the data in the study and final responsibility for the decision to submit for publication.

\section{Funding}

This study was not funded.

\section{Availability of data and materials}

D. Grimaldi and JB. Lascarrou had full access to all the data in the study and had final responsibility for the decision to submit for publication. The database will be public within 3 months after publication at https://icucovadis.com.

\section{Ethics approval and consent to participate}

This study was approved by appropriate regulatory committee in France (CNIL 2217488) and in Belgium (EC n'P2020/253) in accordance with national regulation. Each patient was informed about study. In case of incompetency, next of kin were informed.

\section{Consent for publication}

Not applicable.

\section{Competing interests}

JT is a part-time employee of bioMérieux, an IVD company, and Hospices Civils de Lyon, a university hospital. SE declares consultancies from Aerogen Ltd, research support from Aerogen Ltd, Fisher \& Paykel healthcare, Hamilton medical, travel reimbursements from Aerogen Ltd and Fisher \& Paykel. All other authors declare no conflict of interest.

\section{Author details}

${ }^{1}$ Groupe des anesthésistes réanimateurs, Hôpital Privé d'Antony, Antony, France. ${ }^{2}$ CHRU Tours, Médecine Intensive Réanimation, CIC INSERM 1415 , CRICS-TriggerSEP research network, and INSERM, Centre d'étude des pathologies respiratoires, U1 100, Université de Tours, Tours, France. ${ }^{3}$ Intensive Care, CHU-Charleroi, Marie Curie, Université Libre de Bruxelles, 140, chaussée de Bruxelles, 6042 Charleroi, Belgium. ${ }^{4}$ Réanimation - Médecine Intensive, Centre Hospitalier Public du Cotentin, BP208, 50102 Cherbourg-en-Cotentin, France. ${ }^{5}$ Unité de soins intensifs, Clinique Saint Pierre, Ottignies, Belgium. ${ }^{6}$ Médecine Intensive Réanimation, CHU Besançon, 3 Boulevard FLEMING, 25030 Besançon France. ${ }^{7}$ Service de réanimation, Hospices Civils de Lyon, 5 Place D'Arsonval, Lyon, France. ${ }^{8}$ Laboratoire Commun de Recherche bioMérieux-Hospices Civils de Lyon, Université de Lyon 1, EA7426 PI3 Lyon, France. ${ }^{9}$ Service de Médecine Intensive Réanimation Unité de Sevrage Ventilatoire Et Réhabilitation Centre Hospitalier de BETHUNE, 27 Rue Delbecque, 62660 Beuvry, France. ${ }^{10}$ Médecine Intensive Réanimation, Hôpital Européen Georges Pompidou, Paris Centre U 970 PARCC, Paris, France. ${ }^{11}$ Médecine Intensive Reanimation, District Hospital Center, Boulevard Stephane Moreau, 85000 La Roche Sur Yon, France. ${ }^{12}$ Unité de Soins Intensifs, CHR Mons-Hainaut, Mons, Belgium. ${ }^{13}$ Unité de Soins Intensifs, Centres Hospitaliers de Jolimont, La Louvière, Belgium.

${ }^{14}$ Unité de Soins Intensifs, CHU Ambroise Paré, Mons, Belgium. ${ }^{15}$ Réanimation médico-Chirurgicale CHU Avicennes, Université Sorbonne Paris Nord, Bobigny, France. ${ }^{16}$ Unité de Soins Intensifs, CHU Dinant Godinne, Site Dinant, Dinant, Belgium. ${ }^{17}$ Unité de Soins Intensifs, CHU Dinant Godinne, Site Godinne, Yvoir, Belgium. ${ }^{18}$ Médecine Intensive Réanimation, Assistance Publique - Hôpitaux de Marseille, Hôpital Nord, 13015 Marseille, France. ${ }^{19}$ Centre d'Etudes et de Recherches sur les Services de Santé et qualité de vie EA 3279, Aix-Faculté de médecine, Marseille Université, 13005 Marseille, France. ${ }^{20}$ Réanimation Polyvalente Centre Hospitalier du Pays D'Aix, Aix en Provence, France. ${ }^{21}$ Unité de Soins Intensifs, Clinique Notre Dame de Grâce, Gosselies, Belgium. ${ }^{22}$ Service D'anesthésie-réanimation Chirurgicale, Unité de réanimation Chirurgicale Polyvalente, Hôpitaux Universitaires Henri Mondor, Créteil, France. ${ }^{23}$ Médecine Intensive Réanimation, CHU Nantes, 30 Boulevard Jean Monnet, 44093 Nantes Cedex 9, France. ${ }^{24}$ Soins Intensifs, Hôpital Erasme, ULB, Route de Lennik 808 , 1070 Bruxelles, Belgium.

Received: 24 September 2020 Accepted: 11 December 2020 Published online: 08 February 2021

\section{References}

1. Zhou F, Yu T, Du R, Fan G, Liu Y, Liu Z, et al. Clinical course and risk factors for mortality of adult inpatients with COVID-19 in Wuhan, China: a retrospective cohort study. Lancet. 2020;395(10229):1054-62.

2. Guan W, Ni Z, Hu Y, Liang W, Ou C, He J, et al. Clinical characteristics of coronavirus disease 2019 in China. N Engl J Med. 2020;382(18):1708-20.

3. Camporota L, Vasques F, Sanderson B, Barrett NA, Gattinoni L. Identification of pathophysiological patterns for triage and respiratory support in COVID-19. Lancet Respir Med. 2020;8(8):752-4.

4. Gattinoni L, Coppola S, Cressoni M, Busana M, Rossi S, Chiumello D. COVID-19 does not lead to a "typical" acute respiratory distress syndrome. Am J Respir Crit Care Med. 2020;201 (10):1299-300.

5. Li X, Ma X. Acute respiratory failure in COVID-19: is it "typical" ARDS? Crit Care. 2020;24(1):1-5. https://doi.org/10.1186/s13054-020-02911-9.

6. Gattinoni L, Chiumello D, Rossi S. COVID-19 pneumonia: ARDS or not? Crit Care. 2020;24(1):1-3. https://doi.org/10.1186/s13054-020-02880-z. 
7. Carsana L, Sonzogni A, Nasr A, Rossi RS, Pellegrinelli A, Zerbi P, et al. Pulmonary post-mortem findings in a series of COVID-19 cases from northern Italy: a two-centre descriptive study. Lancet Infect Dis [Internet]. 2020 Jun [cited 2020 Aug 14]. https://linkinghub.elsevier.com/retrieve/ pii/S1473309920304345

8. Menter T, Haslbauer JD, Nienhold R, Savic S, Hopfer H, Deigendesch N, et al. Postmortem examination of COVID-19 patients reveals diffuse alveolar damage with severe capillary congestion and variegated findings in lungs and other organs suggesting vascular dysfunction. Histopathology. 2020;77(2):198-209.

9. Remmelink M, De Mendonça R, D'Haene N, De Clercq S, Verocq C, Lebrun $L$, et al. Unspecific post-mortem findings despite multiorgan viral spread in COVID-19 patients. Critical Care [Internet]. 2020 Dec [cited 2020 Sep 22];24(1). https://doi.org/10.1186/s13054-020-03218-5

10. Ziehr DR, Alladina J, Petri CR, Maley JH, Moskowitz A, Medoff BD, et al. Respiratory pathophysiology of mechanically ventilated patients with COVID-19: a cohort study. Am J Respir Crit Care Med. 2020;201(12):1560-4

11. Schenck EJ, Hoffman K, Goyal P, Choi J, Torres L, Rajwani K, et al. Respiratory mechanics and gas exchange in COVID-19 associated respiratory failure. Ann Am Thorac Soc [Internet]. 2020 May 20 [cited 2020 Aug 14]. https://doi.org/10.1513/AnnalsATS.202005-427RL

12. Haouzi P, Zamir A, Villarreal-Fernandez E, Stauffer D, Ventola L, Ahmad D, et al. Mechanics of breathing and gas exchange in mechanically ventilated patients with COVID-19 associated respiratory failure. Am J Respir Crit Care Med [Internet]. 2020 Jun 24 [cited 2020 Aug 14]. https://doi. org/10.1164/rccm.202004-1041LE

13. Bos LDJ, Sinha P, Dickson RP. Response to "COVID-19 conundrum: clinical phenotyping based on pathophysiology as a promising approach to guide therapy in a novel illness" and "strengthening the foundation of the house of CARDS by phenotyping on the fly" and "COVID-19 phenotypes: leading or misleading?"Eur Respir J. 2020;2002756.

14. Tobin MJ, Laghi F, Jubran A. P-SILI is not justification for intubation of COVID-19 patients. Ann Intensive Care [Internet]. 2020 Dec [cited 2020 Aug 19];10(1). https://doi.org/10.1186/s13613-020-00724-1

15. Grimaldi D, Aissaoui N, Blonz G, Carbutti G, Courcelle R, Gaudry S, et al. Characteristics and outcomes of acute respiratory distress syndrome related to COVID-19 in belgian and french intensive care units according to antiviral strategies. The COVADIS multicenter observational study. [Internet]. Intensive Care Crit Care Med; 2020 Jul [cited 2020 Aug 14]. https://doi.org/10.1101/2020.06.28.20141911

16. Acute respiratory distress syndrome: the berlin definition. JAMA [Internet]. 2012 Jun 20 [cited 2017 Oct 6];307(23). https://doi.org/10.1001/ jama.2012.5669

17. Vestbo J, Hurd SS, Agustí AG, Jones PW, Vogelmeier C, Anzueto A, et al. Global strategy for the diagnosis, management, and prevention of chronic obstructive pulmonary disease: GOLD executive summary. Am J Respir Crit Care Med. 2013;187(4):347-65.

18. Charlson ME, Pompei P, Ales KL, MacKenzie CR. A new method of classifying prognostic comorbidity in longitudinal studies: development and validation. J Chronic Dis. 1987;40(5):373-83.

19. Papazian L, Aubron C, Brochard L, Chiche J-D, Combes A, Dreyfuss D, et al. Formal guidelines: management of acute respiratory distress syndrome. Ann Intensive Care [Internet]. 2019 Dec [cited 2020 Aug 14];9(1). https:// doi.org/10.1186/s13613-019-0540-9

20. on Behalf the COVADIS Study Group, Courcelle R, Gaudry S, Serck N, Blonz G, Lascarrou J-B, et al. Neuromuscular blocking agents (NMBA) for COVID19 acute respiratory distress syndrome: a multicenter observational study. Crit Care [Internet]. 2020 Dec [cited 2020 Aug 14];24(1). https://doi. org/10.1186/s13054-020-03164-2

21. Schoenfeld DA, Bernard GR. Statistical evaluation of ventilator-free days as an efficacy measure in clinical trials of treatments for acute respiratory distress syndrome. Crit Care Med. 2002;30(8):1772-7.

22. Amato MBP, Meade MO, Slutsky AS, Brochard L, Costa ELV, Schoenfeld $D A$, et al. Driving pressure and survival in the acute respiratory distress syndrome. N Engl J Med. 2015;372(8):747-55.

23. on Behalf of the Investigators of the Acurasys and Proseva Trials, Guérin C, Papazian L, Reignier J, Ayzac L, Loundou A, et al. Effect of driving pressure on mortality in ARDS patients during lung protective mechanical ventilation in two randomized controlled trials. Crit Care [Internet]. 2016 Dec [cited 2020 Aug 14];20(1). https://doi.org/10.1186/s13054-016-1556-2
24. Grasselli G, Zangrillo A, Zanella A, Antonelli M, Cabrini L, Castelli A, et al. Baseline characteristics and outcomes of 1591 patients infected with SARS-CoV-2 admitted to ICUs of the Lombardy region, Italy. JAMA. 2020;323(16):1574.

25. Yang X, Yu Y, Xu J, Shu H, Xia J, Liu H, et al. Clinical course and outcomes of critically ill patients with SARS-CoV-2 pneumonia in Wuhan, China: a single-centered, retrospective, observational study. Lancet Respir Med. 2020;8(5):475-81.

26. Beloncle FM, Pavlovsky B, Desprez C, Fage N, Olivier P-Y, Asfar P, et al. Recruitability and effect of PEEP in SARS-Cov-2-associated acute respiratory distress syndrome. Ann Intensive Care [Internet]. 2020 Dec [cited 2020 Aug 14];10(1). https://doi.org/10.1186/s13613-020-00675-7

27. Mauri T, Spinelli E, Scotti E, Colussi G, Basile MC, Crotti S, et al. Potential for lung recruitment and ventilation-perfusion mismatch in patients with the acute respiratory distress syndrome from coronavirus disease 2019*. Crit Care Med. 2020;48(8):1129-34.

28. Grieco DL, Bongiovanni F, Chen L, Menga LS, Cutuli SL, Pintaudi G, et al. Respiratory physiology of COVID-19-induced respiratory failure compared to ARDS of other etiologies. Crit Care [Internet]. 2020 Dec [cited 2020 Sep 21];24(1). https://doi.org/10.1186/s13054-020-03253-2

29. Rello J, Storti E, Belliato M, Serrano R. Clinical phenotypes of SARSCoV-2: implications for clinicians and researchers. Eur Respir J. 2020;55(5):2001028.

30. Haudebourg A-F, Perier F, Tuffet S, de Prost N, Razazi K, Mekontso Dessap A, et al. Respiratory mechanics of COVID-19-versus non-COVID-19-associated acute respiratory distress syndrome. Am J Respir Crit Care Med. 2020;202(2):287-90.

31. Barbeta E, Motos A, Torres A, Ceccato A, Ferrer M, Cilloniz C, et al. SARS$\mathrm{CoV}$-2-induced acute respiratory distress syndrome: pulmonary mechanics and gas exchange abnormalities. Ann Am Thorac Soc [Internet]. 2020 Jun 24 [cited 2020 Aug 14]. https://doi.org/10.1513/AnnalsATS.20200 $5-462 R L$

32. on Behalf of the COVID-19 Spanish ICU Network, Ferrando C, SuarezSipmann F, Mellado-Artigas R, Hernández M, Gea A, et al. Clinical features, ventilatory management, and outcome of ARDS caused by COVID-19 are similar to other causes of ARDS. Intensive Care Med [Internet]. 2020 Jul 29 [cited 2020 Aug 14]. https://doi.org/10.1007/s00134-020-06192-2

33. Grasselli G, Tonetti T, Protti A, Langer T, Girardis M, Bellani G, et al. Pathophysiology of COVID-19-associated acute respiratory distress syndrome: a multicentre prospective observational study. Lancet Respir Med [Internet]. 2020 Aug [cited 2020 Sep 21]. https://linkinghub.elsevier.com/retri eve/pii/S2213260020303702

34. Bellani G, Laffey JG, Pham T, Fan E, Brochard L, Esteban A, et al. Epidemiology, patterns of care, and mortality for patients with acute respiratory distress syndrome in intensive care units in 50 countries. JAMA. 2016;315(8):788.

35. Villarreal-Fernandez E, Patel R, Golamari R, Khalid M, DeWaters A, Haouzi P. A plea for avoiding systematic intubation in severely hypoxemic patients with COVID-19-associated respiratory failure. Crit Care [Internet]. 2020 Dec [cited 2020 Aug 14];24(1). https://doi.org/10.1186/s13054-020-03063 $-6$

36. Bos LDJ, Sinha P, Dickson RP. The perils of premature phenotyping in COVID-19: a call for caution. Eur Respir J. 2020;56(1):2001768.

37. Soumagne T, Lascarrou J-B, Hraiech S, Horlait G, Higny J, d'Hondt A, et al. Factors associated with pulmonary embolism among coronavirus disease 2019 acute respiratory distress syndrome: a multicenter study among 375 patients. Crit Care Explor. 2020;2(7):e0166.

38. Bompard F, Monnier H, Saab I, Tordjman M, Abdoul H, Fournier L, et al. Pulmonary embolism in patients with COVID-19 pneumonia. Eur Respir J. 2020;56(1):2001365

39. Taccone FS, Gevenois PA, Peluso L, Pletchette Z, Lheureux O, Brasseur $A$, et al. Higher intensity thromboprophylaxis regimens and pulmonary embolism in critically III coronavirus disease 2019 patients. Crit Care Med [Internet]. 2020 Aug 7 [cited 2020 Aug 19]. https://doi.org/10.1097/ CCM.00000000000004548

40. Chen L, Del Sorbo L, Grieco DL, Junhasavasdikul D, Rittayamai N, Soliman I, et al. Potential for lung recruitment estimated by the recruitment-toinflation ratio in acute respiratory distress syndrome. A clinical trial. Am J Respir Crit Care Med. 2020;201:178-87.

41. Fan E, Del Sorbo L, Goligher EC, Hodgson CL, Munshi L, Walkey AJ, et al. An Official American Thoracic Society/European Society of Intensive Care 
Medicine/Society of Critical Care Medicine Clinical Practice Guideline: mechanical ventilation in adult patients with acute respiratory distress syndrome. Am J Respir Crit Care Med. 2017;195(9):1253-63.

42. Thompson BT, Chambers RC, Liu KD. Acute respiratory distress syndrome. In: Drazen JM, editor. NE J Med. 2017;377(6):562-72.

43. Burnham EL, Janssen WJ, Riches DWH, Moss M, Downey GP. The fibroproliferative response in acute respiratory distress syndrome: mechanisms and clinical significance. Eur Respir J. 2014;43(1):276-85.
44. Christensen S, Johansen M, Christiansen C, Jensen R, Lemeshow S. Comparison of Charlson comorbidity index with SAPS and APACHE scores for prediction of mortality following intensive care. Clin Epidemiol. 2011;3:203.

\section{Publisher's Note}

Springer Nature remains neutral with regard to jurisdictional claims in published maps and institutional affiliations.
Ready to submit your research? Choose BMC and benefit from:

- fast, convenient online submission

- thorough peer review by experienced researchers in your field

- rapid publication on acceptance

- support for research data, including large and complex data types

- gold Open Access which fosters wider collaboration and increased citations

- maximum visibility for your research: over $100 \mathrm{M}$ website views per year

At BMC, research is always in progress.

Learn more biomedcentral.com/submissions 